\title{
Braço Forte, ¿Mão Amiga?: \\ Un recorrido por las prácticas de contrainsurgencia del ejército brasileño en Haití y Río de Janeiro
}

Juan Ignacio Percoco ${ }^{*}$

\begin{abstract}
Resumen
A la hora de hablar de la participación de Brasil en la Misión de Estabilización de las Naciones Unidas en Haití (MINUSTAH) se tiende a rescatar lo novedoso de su aproximación. La combinación entre operaciones militares y trabajo social fue señalada como un avance a la hora de lidiar con la conflictividad urbana de Puerto Príncipe. Tradicionalmente se ha indicado al despliegue en Haití como el inspirador de las Unidades de Pacificación Policial (UPP) de Río de Janeiro. Sin embargo, quienes realizan estos planteos suelen obviar que dichas técnicas pueden rastrean su origen a las campañas de pacificación coloniales francesas y que éstas cuentan con extensa utilización dentro de Brasil.

En este trabajo describimos el origen y bases doctrinarias de las técnicas de contrainsurgencia francesas que luego serán incorporadas por las Fuerzas Armadas de Brasil. Estas tácticas, aplicadas dentro de Brasil, viajarán a Haití en donde se pulirán y serán reimportadas para su utilización en Río de Janeiro. En última instancia lo que se señala es la existencia de una sinergia y retroalimentación de estas experiencias de pacificación y cómo su origen puede ser encontrado en un pasado mucho más lejano que el establecimiento de MINUSTAH en 2004.
\end{abstract}

Palabras clave: Operaciones de Paz - Contrainsurgencia - UPP - MINUSTAH - Brasil

\section{Braço Forte, ¿Mão Amiga?: \\ A journey through the counterinsurgency practices of the Brazilian army in Haití and Rio de Janeiro}

When it comes to talking about Brazil's participation in the United Nations Stabilization Mission in Haití (MINUSTAH), the novelty of its approach tends to be highlighted. The combination of military operations and social work was pointed out as an advance in dealing with the urban conflict in Port-au-Prince. The deployment in Haití has been traditionally indicated as the inspiration for the Police Pacification Units (UPP) of Rio de Janeiro. However, those who make those statements tend to ignore that these techniques can trace their origin to the French colonial pacification campaigns and that these were widely used within Brazil.

In this paper, we describe the origin and doctrinal bases of French counterinsurgency techniques that will later be incorporated by the Brazilian Armed Forces. These tactics, applied within Brazil, will travel to Haití where they will be polished and re-imported for use in Rio de Janeiro. Ultimately, what we pointed out is the existence of the synergy and feedback of these pacification experiences and how their origin can be found in a much more distant past than the establishment of MINUSTAH in 2004.

Key words: Peace Operations - Counterinsurgency - UPP - MINUSTAH - Brazil

TRABAJO RECIBIDO: 30/10/2020 TRABAJO ACEPTADO: 21/03/2021

Esta obra está bajo una licencia internacional https://creativecommons.org/licenses/by-sa/4.0/

\footnotetext{
*Becario doctoral Universidad Nacional de Rosario (UNR)-Universidad Nacional de San Martín (UNSAM)-Consejo Nacional de Investigaciones Científicas y Técnicas (CONICET). Licenciado en Relaciones Internacionales, Universidad Nacional de Rosario (UNR, Argentina). Docente e investigador miembro del Área de Estudios Internacionales de la Universidad Nacional de San Martin (UNSAM, Argentina). Correo electrónico: juanignacio.percoco@gmail.com
} 


\section{Introducción}

A la hora de hablar de la participación de la República Federativa de Brasil en la Misión de Estabilización de las Naciones Unidas en Haití (MINUSTAH) se suelen trazar unos puentes imaginarios que unen a los barrios marginales de Puerto Príncipe con las favelas de Río de Janeiro. La narrativa predominante parte de la idea que el tan promocionado "Brazilian way of peacekeeping" desplegado en Bel Air y otros distritos haitianos fue la base y el origen de lo que luego serían las denominadas Unidades de Pacificación Policial (UPP). Sin embargo, sostener este relato significaría ignorar una extensa historia de operaciones de pacificación llevadas adelante por el Estado brasileño en su propio territorio. En tal sentido, según han declarado aquellos involucrados en el despliegue en Haití (Schuberth, 2017, p. 4), los efectivos brasileños junto con actores de la sociedad civil han sido llamados a la isla precisamente por el conjunto de experiencias previas de estos actores en la lucha urbana contra pandillas armadas.

El presente trabajo busca retomar la historia de este tipo de operaciones, señalando su origen y bases doctrinarias en las técnicas de contrainsurgencia diseñadas por las fuerzas coloniales francesas, que luego fueron incorporadas por las Fuerzas Armadas de Brasil. Estas tácticas que serán aplicadas en diversas ocasiones en territorio brasileño viajarán a Haití, en donde se pulirán y volverán a ser reimportadas para su utilización en los morros de Río de Janeiro. Lo que buscamos argumentar es la existencia de un hilo conductor entre las prácticas, la doctrina de contrainsurgencia con el despliegue de estabilización en Haití y la política de pacificación en los morros de Río. En tal sentido, identificamos a las UPP como el último estadio en un proceso de perfeccionamiento de técnicas de control urbano. El mismo comienza con las experiencias y la arquitectura doctrinaria desarrollada por Francia, que es adoptada por las Fuerzas Armadas de Brasil, exportadas a las calles de Cité Soleil y Bel Air en donde son pulidas y luego reimportadas a Río de Janeiro.

Este trabajo se articula en 3 secciones. En la primera parte rastrearemos los orígenes del concepto moderno de contrainsurgencia. Recorreremos sus primeras expresiones en la campaña de Argelia y describiremos cómo llegó a Brasil para ser incorporado por sus oficiales a mediados del Siglo XX como técnica anti subversiva contra el "enemigo comunista". En la segunda sección analizaremos las prácticas del Estado brasileño en las favelas de Río de Janeiro, así como en las zonas más conflictivas de Puerto Príncipe. Por medio de ese recorrido procuramos identificar los elementos conceptuales y doctrinarios señalados más arriba en los despliegues concretos llevados adelante en esos territorios. Finalmente, presentamos unas reflexiones finales en torno a todo lo expuesto, donde articularemos el desarrollo doctrinario e histórico realizado en las secciones previas para sostener la premisa presentada.

Todo lo anterior lo realizaremos mediante una revisión bibliográfica de aquellos documentos y obras en donde se han plasmado los lineamientos doctrinarios; asimismo se traerán a análisis los casos históricos para poder sustentar empíricamente lo sostenido en el trabajo.

\section{Contrainsurgencia, desarrollo de una doctrina}

Coincidiendo con el planteo de David Kilcullen (2012, p. 129), podemos afirmar que la acción genérica de suprimir insurrecciones y rebeliones internas (lo que el autor llama contrainsurgencia con "c" minúscula) es una actividad tradicional del Estado que se remonta a los orígenes del mismo. Sin embargo, en la actualidad a la hora de hablar de contrainsurgencia hacemos referencia a un conjunto muy específico de actividades. Lo que Kilcullen (2012, p. 130) denomina Contrainsurgencia con "C" mayúscula o COIN".

Bajo este rótulo normalmente se hace referencia a un concepto de reciente elaboración. Originado en la década del ' 60 , en el marco del proceso de descolonización del tercer mundo, se

\footnotetext{
${ }^{1}$ Durante este trabajo utilizaremos de manera indistinta estos dos conceptos, sin embargo, no respetaremos el uso de la "C" mayúscula planteado por Killculen.
} 
ha utilizado para nombrar a las acciones militares, paramilitares, políticas, económicas, psicológicas y civiles llevadas adelante por un gobierno y sus aliados extranjeros para derrotar a un movimiento insurgente. Bajo este prisma se suele entender a la insurgencia como un movimiento organizado con el objetivo de derrocar a un gobierno mediante la subversión y el conflicto armado. Ante esa amenaza, y como se plantea en el manual de contrainsurgencia del ejército de los EEUU (Petraeus \& Amos, 2009), las antiguas doctrinas de los ejércitos industriales son dejadas de lado, dado que no brindan respuestas efectivas ante el combate irregular y asimétrico que predomina en estas campañas. En el marco de un escenario global -en donde los conflictos son crecientemente urbanos y las batallas son luchadas "entre la gente" (Smith, 2012)la contrainsurgencia se presenta como una alternativa militar centrada en la población civil, concibiendo a esta última como "parte del terreno" y cuyo apoyo es uno de los principales determinantes del éxito.

Sin embargo, el verdadero origen de esta doctrina hay que buscarlo en un pasado aún más lejano. Si deseamos inquirir sobre la genealogía de la contrainsurgencia contemporánea hace falta remontarse a las campañas de pacificación coloniales llevadas adelante por Francia en el Siglo XIX.

A principios del Siglo XIX, en el desierto de Argelia, el Mariscal Thomas Robert Bugeuad (1784-1849) se enfrentó con la ausencia de los elementos esenciales de la guerra europea: no existían posiciones enemigas que pudieran ser asaltadas, no había fortificaciones dado que el territorio no podía ser retenido y la búsqueda de la batalla decisiva era fútil. En resumen, para retomar a von Clausewitz, no existía "el centro de gravedad del conflicto" (Rid, 2010, p. 733). En un teatro de operaciones donde la fuerza adversaria era difusa y la superioridad técnica e incluso numérica de los ejércitos europeos no se traducía en resultados duraderos, la respuesta de Bugeaud fue emular al adversario, "volverse uno mismo difuso" (Rid, 2010, p. 735) en sus palabras. De esa manera surge la razzia como un "golpe de mano", una operación rápida y precisa que desciende velozmente sobre la población y apunta a sus granos y ganado. De esta manera las operaciones militares se centraron en la población por necesidad, dada la ausencia de blancos más tradicionales para perseguir.

Sin embargo, la razzia no era la única dimensión de esta nueva modalidad de guerra llevada adelante por Bugeaud. Su contracara era una institución más ingeniosa y menos feroz, estamos hablando del bureaux arabe (en español, la Agencia de Asuntos Árabes). Esta institución se planteó con la misión de establecer relaciones con las tribus tanto bajo autoridad francesa como independientes para "explicar la política y operaciones de Francia", pero a su vez para transmitir información a las diferentes agencias de seguridad (Rid, 2010, p. 737). La estrategia era utilizar la cooptación y cooperación para limitar el peligro que pudieran representar las principales familias de cada región.

De la misma manera que el nombre de Bugeaud ha quedado vinculado con la campaña de Argelia, lo ha sido el del General de División Joseph-Simon Galliéni (1849-1916) con el destino de Madagascar. Militar experimentado en situaciones de pacificación colonial en África y el sudeste asiático, al arribar a la nación insular en 1896 lo hizo con un método de contrainsurgencia probado y perfeccionado por años de experiencias en el terreno.

A los pocos días de haber tomado posesión de su mando, Galliéni emitió un conjunto exhaustivo de órdenes en donde resaltaba que la primera preocupación de los comandantes en el terreno debería ser "traer calma y tranquilidad a la población" en torno a la seguridad de los sectores asignados (Rid, 2010, p. 750). Esto debía ser acompañado con una demostración de fuerza que debía ser realizada en todas direcciones y a toda hora para poder demostrar a los civiles el poderío militar francés, y a su vez inspirar confianza en su compromiso con la seguridad de estos.

La primera medida llevada adelante por Galliéni fue crear una institución militar, el territoire militaire, que agruparía todo el poder de la administración central. La misma concentraría las responsabilidades por las acciones políticas y militares en la isla, y estaría 
dividida en 7 oficinas, de las cuales resaltaba la 3ra (asuntos civiles) y la 6ta (asuntos indígenas). La oficina de asuntos civiles tenía a su cargo las cuestiones políticas, el presupuesto local, el sistema judicial, y las principales cuestiones atenientes a la explotación de los recursos naturales del territorio. Por su parte, la oficina de asuntos indígenas era la responsable de las cuestiones educativas y religiosas. En conjunto, con la subdivisión de tareas en estas oficinas, Galliéni implementó una nueva estructura territorial. Se establecieron 7 distritos (cercles) a cargo de un coronel, los cuales a su vez se subdividieron en secteurs en donde el poder militar y civil quedó en manos de capitanes y tenientes. Este esquema capilar funcionaba bajo el principio guía de que los líderes militares que cumplieran tareas político-administrativas pudieran desplegar el mayor margen de iniciativa posible en las aldeas a su mando. En esencia, un sistema simple y racional que uniera bajo un solo mando el comando militar, los poderes administrativos y todos los escalafones de la jerarquía.

Este conjunto de medidas fue un rotundo éxito y para finales de 1896 la seguridad del territorio se encontraba prácticamente restablecida, habiendo sido los insurgentes cooptados o expulsados a zonas áridas fuera de la región central de la isla. En palabras de Galliéni (Rid, 2010, p. 750), la clave del éxito fue "la combinación de acción política con acción militar" para "entrar en un contacto íntimo con la población, explorar sus tendencias, su mentalidad, y esforzándose para satisfacer sus necesidades con la intención de acercarlos a través de la persuasión a las nuevas instituciones".

Las operaciones en Argelia y Madagascar marcarían la pauta de operaciones de pacificación coloniales, en donde las poblaciones civiles cobrarían progresivamente una importancia mayor. Estas no solo necesitaban ser protegidas de la violencia insurgente, sino que también persuadidas de que trabajar con las fuerzas de la metrópoli era más beneficioso que permitir el ascenso de los rebeldes al poder.

La base de la contrainsurgencia moderna se sentó en esos escenarios; el objetivo central será atacar a la base de la insurgencia convirtiendo a la población local en una aliada. Para tal fin se construirán mercados y fomentará el comercio, se trazarán líneas de comunicación y se protegerán a los civiles y fortificarán aldeas (Rid, 2010, p. 752). En resumen, el acercamiento francés a la contrainsurgencia se sostuvo en un énfasis en fuerzas expedicionarias flexibles, "el rol social del oficial" como un agente de la autoridad política metropolitana, y el uso de la brutalidad para inspirar temor en la población indígena (Chisholm, 2018, p. 14).

Estas experiencias desarrolladas durante el Siglo XIX y principios del Siglo XX fueron rescatadas en los primeros años de la segunda posguerra para emerger nuevamente en la doctrina de la Guerre Révolutionnaire.

A finales de la década del " 50 e inicios de la década del " 60 las denominadas "guerras de liberación nacional", en la antigua periferia colonial europea, se encontraban en ascenso y la URSS había plegado su apoyo a aquellos que se enfrentaban a las metrópolis occidentales. La naturaleza de estas guerras "modernas" sería la de una guerre en surface -en vez de una guerre de front, luchada en áreas densamente pobladas que debían ser controladas en vez de los típicos frentes de batallas, requiriendo que la acción política, administrativa, social y económica sea tan importante para separar a la población del enemigo como las operaciones militares directas. Ante la centralidad que juega la población civil en este conflicto, se plantea que la respuesta apropiada sería la de ganar sus "corazones y mentes" exponiendo la falsedad de la doctrina revolucionaria e inculcando una alternativa. El corazón de esta respuesta se encontraba en la guerra psicológica (Chisholm, 2018, p. 15) y sus parámetros se hallan en la fórmula utilizada para definir este tipo de conflicto por Bonnet (1963, p. 60), "partisan warfare + psychological warfare = Revolutionary warfare".

Para esta visión, la guerra partisana implicaba lidiar con un enemigo que se rehusaba a luchar abiertamente y demandaba una respuesta similar a la guerra colonial del Siglo XIX. De tal manera, se volvió a pensar en asegurar a las poblaciones civiles mediante la acción de pequeñas unidades que combinaban actividades policiales y asuntos administrativos con operaciones 
militares. Por su parte, la acción psicológica estaba destinada a las mentes de la población ganada por la insurgencia, que debían ser conquistadas nuevamente por medio del uso de técnicas de "reeducación" para contrarrestar la "influencia perniciosa" de la propaganda comunista (Chisholm, 2018, pp. 15-16).

En línea con el devenir de esta estructura doctrinaria, y comenzando a enfocarnos en cómo ha permeado en la periferia, vemos que la misma se transmitió a través de diversos canales por los diferentes ejércitos de las Américas, dejando su impronta hasta la actualidad.

En principio resulta fundamental rescatar la obra de David Galula quien publicaría, en 1964 en los EEUU, su texto más reconocido, Counterinsurgency Warfare: theory and practice. Este trabajo, que se sustenta en un solo caso (por lo que no podría ser considerado como una teoría general de COIN), representa más bien una extrapolación de las tácticas utilizadas en Argelia durante la campaña contra el Ejército de Liberación Nacional (ALN, por sus siglas en francés). El libro de Galula ha mantenido preeminencia en el debate doctrinario en el país del norte y con el tiempo se convirtió en una de las obras más citadas por el General David Petraeus en el novel manual de campo de contrainsurgencia del ejército de los EEUU en 2006.

En su libro, Galula plantea que el insurgente tenderá a movilizar a la población civil a su favor dada la debilidad estructural de sus recursos; en este escenario, para quien lleve adelante tareas de contrainsurgencia resultará de vital importancia granjearse su apoyo. Justamente al ser la población el principal campo de batalla de esta guerra, las acciones insurgentes poseen un carácter esencialmente político $\mathrm{y}$, por lo tanto, las respuestas a éstas deben ser diagramadas atendiendo siempre al impacto público de las mismas (Galula, 1964, p. 7). El autor señala que esto se encuentra directamente relacionado con el origen de las insurgencias en tanto que se identifica a la marginalización y a la pobreza como catalizadores claves (Mendoça, 2017, p. 59). En consonancia, las medidas que deben ser llevadas adelante necesitan la legitimación de líderes locales moderados y dar cuenta de las demandas de la población. De esta manera, se apunta a erosionar la base sobre la que se sostienen los movimientos insurgentes.

En términos operativos Galula detalló algunos pasos que desarrolla como principios generales para el contrainsurgente (Mendoça, 2017, p. 58). Habiendo elegido el área donde deben ingresar las Fuerzas Armadas del Estado, éstas deben aspirar a la destrucción o expulsión, en la medida de lo posible, del grupo insurgente. En conjunto con lo anterior, las fuerzas de seguridad deben establecer bases o "Puntos Fuertes" dentro del territorio desde donde poder tener un mejor control de la población y prevenir cualquier intento de reorganización de la guerrilla. De manera simultánea es preciso desarrollar un plan activo de propaganda a fin de apelar a la población y si no se consigue su cooperación directa, al menos aspirar a la pasividad de la misma (Mendoça, 2017, p. 59). Por último, se busca el restablecimiento de la autoridad sobre la región mediante el aislamiento, incluso físico, de la población y el grupo insurgente, y a su vez, el uso de instrumentos de inteligencia para acceder a quienes forman parte de la organización rebelde.

A pesar de la influencia central jugada en los EEUU por David Galula, en el sur del continente uno de los principales referentes intelectuales fue Roger Trinquier. El Teniente Coronel Roger Trinquier, veterano de las campañas coloniales de Indochina y Argelia, publicó su libro Modern Warfare: a French view of counterinsurgency en 1961. A lo largo de toda su obra se observa la importancia del aspecto político del conflicto a la hora de estudiar las victorias de los combatientes irregulares.

Trinquier analiza a estas guerras de insurrección como sistemas interconectados de acciones en el campo político, económico, psicológico y militar; en donde el favor de la población resulta clave para la victoria (Trinquier, 2006, pp. 6-8). Este apoyo debe ser ganado mediante la garantía de seguridad a los civiles y sostenido mediante activas campañas de propaganda, así como la prestación de servicios sociales en la zona luego de una operación militar (Mendoça, 2017, p. 52). Según el autor, sin este sostén y confianza, "cualquier publicidad, cualquier solución, por ingeniosa que sea, no tendrá efecto en una población contaminada por organismos clandestinos que la infectan como un cáncer y la aterrorizan" (Trinquier, 2006, p. 49). Esta 
conjunción de construcción de infraestructura básica más patrullaje e incursiones para erradicar a los insurgentes es lo que conforma para el autor una política de pacificación ${ }^{2}$.

La transmisión del trabajo de Trinquier a Brasil, junto con los demás autores que construyeron la doctrina de la Guerre Révolutionnaire, proviene de conexiones directas con Francia y al mismo tiempo de una ruta indirecta por medio de Argentina.

En el primer caso, los vínculos construidos por medio de la Misión Militar francesa que operó entre 1919 y 1940, involucra a un importante número de oficiales que para la década del '50 habían logrado ascender entre los rangos del ejército brasileño (Chisholm, 2018, p. 20; Martins Filho, 2014, p. 170). Esta cooperación de preguerra, que marcó profundamente el pensamiento militar brasileño (Svartman, 2006; Costa, 1994, p. 77), se manifiesta principalmente en un ethos en donde el oficial entrenado en estas escuelas se percibía a sí mismo como el constructor de una nación, un estudioso de sus problemas y alguien que ha creado teorías acerca del país y de su futuro (Martins Filho, 2014, p. 171). Para la época que el ejército francés comenzó a formular la doctrina de la Guerre Révolutionnaire, existía una fuerte afinidad por el pensamiento francés y una conexión institucional remanente entre ambos ejércitos (Chisholm, 2018, p. 20). La segunda fuente identificada por varios autores (Mendoça, 2017; Chisholm, 2018; Martins Filho, 2014; Carlson, 2000; Perelli, 1992; Porch, 2013) fue la misión informal francesa a Buenos Aires entre 1957 a 1963. Como resultado de ésta comenzaron a surgir artículos académicos en la Revista de la Escuela Superior de Guerra referidos a la doctrina en 1958, seguido por entrenamiento propiamente dicho en 1959. Esta creciente presencia y producción académica fue aprovechada por los oficiales brasileños para confeccionar su propia currículo, la cual fue plasmada en el programa de contrainsurgencia inaugurado en la Escuela Superior de Guerra (ESG) de Río de Janeiro en 1962 (Chisholm, 2018, p. 20; Martins Filho, 2014). En este sentido la mayoría de los trabajos producidos por los brasileños implicaban un resumen o parafraseo de la doctrina francesa, con el esfuerzo puesto centralmente en acomodarla a las especificidades de las condiciones brasileñas (Chisholm, 2018, p. 23).

Por último, en lo que respecta a la influencia de Trinquier y además de las dos conexiones mencionadas, cabe destacar la presencia del general francés Paul Aussaresses (1918-2013) en el Centro de Instruaço de Guerra na Selva (CIGS) en Manaos. El General, habiendo servido como oficial en la Guerra de Argelia, brindó cursos en los EEUU basándose principalmente en la obra de Trinquier y especializándose en el entrenamiento de "interrogatorios coercitivos" 3 (Mendoça, 2017, p. 64).

Como vimos a lo largo de esta primera sección, la influencia gala en la formulación de una doctrina de contrainsurgencia en Brasil es clara y esto puede constatarse en las referencias a los autores franceses halladas al analizar los documentos y artículos académicos de la época, así como en las prácticas de los militares brasileños durante la dictadura de 1964. Esta influencia aún se siente y, como se observa en el apartado siguiente, es posible identificar sus rastros en las misiones de pacificación emprendidas por el ejército brasileño, tanto en Haití como en las Fuerzas de Pacificación dirigidas al escenario interno (Mendoça, 2017, p. 69).

\section{Viaje de ida y vuelta: Río de Janeiro, Puerto Príncipe, Río de Janeiro}

En esta sección desarrollaremos un recorrido por nuestros casos de estudio mediante los cuales sostenemos la premisa planteada al comienzo de este trabajo.

\footnotetext{
${ }^{2}$ Vale mencionar que tanto en las obras de los autores del Siglo XIX como aquellos autores contemporáneos los términos contrainsurgencia y pacificación se emplean casi indistintamente. Esta cuestión se retomará, brevemente, más adelante.

${ }^{3}$ Eufemismo poco feliz que hace referencia a técnicas de tortura aplicadas sobre prisioneros.
} 


\subsection{Partimos en Río}

Antes de avanzar, debemos hacer alguna referencia a los orígenes de la violencia que se manifiesta en las calles de Río de Janeiro. Mientras que los argumentos que enfatizan los factores estructurales y situacionales en la dinámica del crimen violento se encuentran bien desarrollados (Sampó y Troncoso, 2015), una razón fundamental que se halla detrás del incremento de la violencia en Brasil ha sido la debilidad del Estado y el aumento de áreas urbanas en donde este último no puede ejercer sus funciones, ya sea por incapacidad o por desidia. Rastros de inequidades persistentes que han influido en la manera en cómo se ha utilizado la fuerza pública, un legado de prácticas represivas escabroso (Caldeira, 2002; Cardia, Adorno y Poleto, 2003) y una falta crónica de accountability junto con una remuneración históricamente baja a sus miembros, han construido en los diferentes estamentos policiales de Brasil una cultura de impunidad y corrupción (Hoelscher \& Norheim-Martinsen, 2014, p. 961).

En el caso puntual de Río de Janeiro, la violencia urbana atraviesa las categorías sociales, políticas, económicas e institucionales (Moser, 2004; Winton, 2004). La segregación socioespacial entre ricos y pobres de esta megaurbe y su característica fragmentación urbana son claras consecuencias del proceso de rápida urbanización e industrialización llevado adelante por el país en la segunda mitad del S.XX (Martine \& McGranahan, 2010).

Durante el boom de la comercialización de la cocaína en la década de los '80, las pandillas criminales dedicadas al narcotráfico proliferaron y el crimen organizado comenzó a dominar la vida social, económica e incluso política de las favelas (Koonings \& Kruijt, 2009; Perlman, 2010; Cardia, 2000; World Bank, 2011; UNHABITAT, 2007). El contexto desde los '90, de ajuste neoliberal y consecuente aumento de la exclusión y marginalización de los sectores más vulnerables (Sanchez, 2006; Koonings \& Kruijt, 2007, 2009), fue un terreno fértil para estos actores armados y "gestores de la violencia" que aprovecharon la retracción estatal para crear alternativas ilegales de poder e ingresos (Werling, 2014, p. 4).

La visibilidad de los conflictos violentos entre los involucrados en este circuito ilegal propició la instalación de un nuevo enemigo del orden ya asociado con el "negro, pobre, favelado y migrante": el narcotraficante (Mendoça, 2017, p. 120). Desde la década del '80 el enemigo interno (previamente el subversivo) es actualizado y se lo comenzará a identificar con la figura del traficante de drogas, el cual será combatido desde la lógica de la doctrina de contrainsurgencia.

Primeramente, las respuestas estatales ante la violencia e informalidad urbana han sido intervenciones esporádicas en donde primó el abuso de la fuerza y autoridad policial (World Bank, 2011; Cano, 2012). Debido a los sistemáticos fracasos de estas políticas de "mano dura" 4 durante los '90 se comenzaron a diseñar y buscar implementar iniciativas más progresistas de policiamiento comunitario y de proximidad (Rodgers, 2009).

Las estrategias de pacificación de las favelas en Río han sido llevadas a cabo por diferentes actores armados del Estado. Por un lado, han actuado efectivos del ejército y por el otro han intervenido diversas divisiones de la Policía Militar del Estado de Río de Janeiro (PMRJ) ${ }^{5}$.

\footnotetext{
${ }^{4}$ No solo estas políticas no brindaban los resultados esperados, sino que también generaban un costo político difícil de sostener. Para el 2007 la policía de Rio de Janeiro era la responsable por la mayoría de los homicidios intencionales en algunas favelas de la ciudad (Schuberth, 2017, p. 9).

${ }^{5}$ De acuerdo con lo planteado por la Constitución Federal de 1988, cinco instituciones tienen a su cargo la seguridad pública de Brasil: la Polícia Federal, la Polícia Rodoviaria Federal y la Polícia Ferroviária Federal mientras que a nivel estatal se encuentran la Polícia Civil y la Polícia Militar (junto con el cuerpo de bomberos, los cuales se encuentran formalmente unidos a esta última). Dado que la tarea de la Polícia Federal se encuentra concentrada en control de frontera y debido a lo específico de las responsabilidades de la policía caminera y ferroviaria, el grueso del trabajo recae sobre la Polícia Civil, quien lleva adelante las tareas investigativas, y la Polícia Militar, quien realiza las tareas ostensivas de policiamiento, como patrullas, arrestos y control general del orden público (Harig, 2015, p. 153). Es de mencionar que existe una vinculación estrecha entre los oficiales de la Polícia Militar y el ejército, dado que estos primeros cuentan como reservas y auxiliares de estos últimos (CEEEx, 2007, p. 16). La misma Carta Magna, por
} 
Desde principios de los ' 90 se produjeron dos fenómenos casi en paralelo. Por un lado, se originaron las primeras demandas para la intervención militar de Río, la cual se llevó a cabo en el marco del esquema de seguridad de la Conferencia sobre Medio Ambiente de las Naciones Unidas de 1992 (Harig, 2015, p. 145). Unos años más tarde, en octubre de 1994, se llevó adelante la "Operación Río", realizada con el objetivo explícito de combatir el crimen organizado en la ciudad mediante la ocupación por parte del ejército de más de 50 favelas durante dos meses (Rodrigues, 2016, p. 70; Mendoça, 2017, p. 123; Harig, 2015, p. 145). Finalmente, en el periodo 1994/5, se llevó adelante por las Fuerzas Armadas la ocupación del vecindario Parque Roquete Pinto y en la misma se implementaron técnicas que veremos utilizadas en las calles de Haití. Similar al concepto de "Punto Fuerte" ("Ponto Forte"), los soldados establecieron posiciones fortificadas permanentes como base para patrullas regulares. A su vez, se brindaron servicios sociales básicos y atención médica primaria a la población (Harig, 2015, p. 145).

El segundo fenómeno comienza a delinearse entre 1993 y 1994. En esos años la Policía Militar, en asociación con la ONG "Viva Río", promovió una experiencia de patrullaje comunitario a partir de la creación del Grupamento de Aplicação Prático-Escolar (GAPE), destinado a proporcionar servicios de seguridad pública dentro de aquellas comunidades en situación de emergencia (Misse \& de Carvalho, 2008, p. 6675). Estas eran unidades policiales especializadas en trabajar en barrios marginales. La iniciativa surgió del intento de la ONG "Viva Río" de convencer al gobierno del estado para que adoptara el modelo que ya había reducido considerablemente las tasas de delitos violentos en varias ciudades de los EEUU, principalmente en Boston (Misse \& de Carvalho, 2008, p. 6675).

Sobre la base de este proyecto se lanzó, a partir de septiembre del 2000, el Grupamento de Policiamento em Áreas Especiais (GPAE). Según la definición del Plan de Políticas Públicas, Seguridad, Justicia y Ciudadanía del Estado de Río de Janeiro (2000), el GPAE partía de una filosofía de empleo policial diferente de la tradicional, alejándose de la idea de defender al Estado y centrando su acción en la defensa de los ciudadanos y comunidades en general. El objetivo era reemplazar la lógica policial de la incursión esporádica y la ocupación del territorio, mediante la vigilancia con políticas adaptadas a la realidad local y la participación popular. GPAE tenía el objetivo de establecerse en los barrios bajos (Misse \& de Carvalho, 2008), donde el Estado sólo estaba presente de manera represiva. Los proyectos sociales, en asociación con los gobiernos municipales, estatales y federales, e incluso con la iniciativa privada, se implementaron con el objetivo de acercar a los agentes de policía a los residentes locales. El GPAE llevó adelante estas acciones de asistencia social conjuntamente con la ONG "Viva Río", algo que las Fuerzas Armadas brasileñas repetirán en Haití.

A pesar de todo esto, las propuestas mencionadas fueron escasamente financiadas y apoyadas a regañadientes por las autoridades, por lo que ninguna de ellas pudo alterar de manera sostenida el escenario de seguridad en Río de Janeiro (Harig, 2015, p. 146).

En este punto, podemos determinar que existe un modelo de intervención sobre áreas conflictivas de larga data en Brasil. El mismo combina una práctica represiva vigorosa junto con apoyo de varias dependencias públicas para reafirmar la presencia del Estado en un terreno en disputa con elementos irregulares. Detectamos en las primeras operaciones militares y primeros planes de policiamiento de proximidad en la zona aquellos rastros de la doctrina de contrainsurgencia que hemos planteado más arriba.

En la próxima sección veremos cómo estos elementos fueron llevados adelante por los cascos azules brasileños en Haití.

otro lado, establece los escenarios en donde las Fuerzas Armadas pueden ser utilizadas en operaciones dentro del territorio nacional. Estas operaciones denominadas de "Garantía de la Ley y el Orden" están previstas dentro del Art. 142 y por un conjunto de leyes complementarias que han ido detallando el alcance de las mismas a lo largo del tiempo. 


\subsection{Hacemos escala en Haití}

Haití ha sido descripto como el primer Estado permanentemente fallido del mundo (International Crisis Group, 2007; Lemay-Hébert, 2014) sin embargo, coincidimos con el planteo de James Cockayne (2009, p. 77) el cual afirma que es altamente discutible la existencia de un Estado, de corte weberiano, que pueda fallar en primer lugar. En vez de ser aquél que detenta el monopolio legítimo de la coacción física, el Estado en Haití ha sido uno más de los "jugadores" en lo que el autor denomina la "competencia por la protección" (Cockayne, 2009, p. 77), es decir la competencia entre dos o más actores sociales que disputan la "protección" de una población a través del control de la violencia ejercida sobre ella, independientemente de cómo se encuentre legitimada.

En el marco de una nueva mutación de la "alianza" que sostenía al presidente Jean Betrand Aristide desde su elección en 2001, un heterogéneo conjunto de combatientes irregulares ${ }^{6}$ (chimères) comenzó su avance hacia Puerto Príncipe dejando a su paso una estela de destrucción. La situación fue resuelta luego de la forzada partida de Aristide el 29 de febrero de 2004 y el despliegue en el mismo día de una fuerza multinacional compuesta por tropas de los EEUU, Francia, Canadá y Chile. Para finales de abril se había establecido un gobierno de transición, y el Consejo de Seguridad de las Naciones Unidas había promulgado la resolución 1542 que establecía la creación de la Misión de Estabilización de las Naciones Unidas en Haití (MINUSTAH). Dicha resolución le otorgaba un mandato amplio para que sus elementos constituyentes provean seguridad, emprendan tareas de capacitación y construcción de capacidad de las fuerzas de seguridad y judiciales, así como un apoyo directo a la restitución del orden constitucional (Cockayne, 2009, p. 82).

MINUSTAH fue la primera misión de las Naciones Unidas en incorporar de manera explícita el término de "estabilización" en su nombre. Este concepto, carece de una tipificación canónica dentro de la doctrina de Naciones Unidas. Sin embargo, podemos remitirnos a las concepciones de aquellos Estados que influenciaron en la redacción de la resolución que le dio vida a la MINUSTAH para buscar un poco de claridad al respecto. De esta manera, vemos que todas se refieren a la estabilización como un medio de responder a un conflicto intraestatal, así como aclaran que su objetivo es la persecución de un objetivo político final. Finalmente, y a pesar que los contornos de la estabilización son definidos de manera muy amplia, todas las concepciones remiten a un conjunto extenso de medidas integradas o coordinadas entre civiles y militares destinadas a influenciar de manera multidimensional las diferentes aristas del conflicto (Ministère de la Défense de la République Française, 2010; UK Government - Stabilization Unit, 2014; US Joint Chiefs of Staff, 2016).

Teniendo en cuenta lo mencionado, vemos que el mandato de MINUSTAH se contrapuso a la tradición de Brasil a la hora de sostener soluciones no violentas a los conflictos (Harig, 2019, pp. 8-9). La misión en Haití significó un momento histórico en las contribuciones de Brasilia a las operaciones de paz. El país brindó la mayor parte del contingente militar de la intervención, algo más de 37.000 efectivos ${ }^{7}$, y contrariamente a la práctica habitual, los generales brasileños actuaron como force commanders a lo largo de toda la misión (Harig, 2019, p. 8).

\footnotetext{
${ }^{6}$ El origen del "ejército caníbal" como se denominaban estas fuerzas debe buscarse en el intento llevado adelante por Aristide, a partir del 2001, de generar una estructura de protección frente a sus propias fuerzas de seguridad, de las cuales desconfiaba. La solución encontrada fue la de armar a organizaciones de base existentes dentro de la estructura de su propio partido. Las chimères, como serian llamadas, no tardaron en generar sus propias prácticas criminales. Luego del asesinato de uno de los líderes de esta facción, Amior Métayer en septiembre del 2003, sus simpatizantes unieron fuerzas con Guy Philippe, antiguo oficial de la Policía Nacional de Haití con vínculos al narcotráfico y ex miembros de las Fuerzas Armadas (International Crisis Group, 2007).

${ }^{7}$ Este número cobra mayor relevancia al considerar que desde 1948 Brasil ha aportado un total de 50.000 tropas, por lo que la contribución a MINUSTAH representa algo más del $70 \%$ de los efectivos comprometidos históricamente por el país.
} 
Para decidir la "competencia por la protección" (Cockayne, 2009) a favor del Estado, MINUSTAH había sido, al comienzo de su mandato, encargada de lidiar con la amenaza que significaban las pandillas urbanas ${ }^{8}$ mediante redadas e incursiones militares coercitivas en territorios dominados por aquellas (Schuberth, 2017, p. 7). Enfrentadas con estas fuerzas no convencionales que poseían una alta (pero muy localizada) legitimidad social (Cockayne, 2014, p. 737), MINUSTAH luchó por incorporar el uso de la fuerza en una estrategia más amplia de consolidación estatal. Rápidamente resultó claro que la misión no poseía el marco estratégico necesario para entender y lidiar con este tipo de adversarios "rizomáticos"". Ante este escenario en donde se misturaban política electoral, con guerra de pandillas y una economía ilegal altamente competitiva, MINUSTAH enfrentó la dificultad de haber encarado el problema como una simple cuestión de orden público y no como una amenaza estratégica al mandato principal de la misión: la estabilización del orden político-estatal (Cockayne, 2014, pp. 744 - 745).

Las primeras señales de las complicaciones de MINUSTAH para dominar el ambiente de seguridad emergieron rápidamente luego de su despliegue. La escasa capacidad y limitado alcance del gobierno interino y sus socios internacionales a principios del 2004 habilitaron a que milicias compuestas por ex miembros de las Fuerzas Armandas ${ }^{10}$ aprovecharan el vacío de poder en las áreas rurales del norte y este del país. Por su parte, las chimères y otras formaciones políticas informales evolucionaron en pandillas y grupos de vigilantes (Cockayne, 2014, p. 745). Para principios del 2005, estos diversos actores, en conjunto con las baz ya existentes, se convirtieron en la autoridad de facto de sectores significativos del territorio, en especial en las áreas marginales urbanas.

En ese marco y bajo fuertes críticas tanto del gobierno local como de algunos miembros prominentes de las Naciones Unidas, el comando de MINUSTAH buscó realizar demostraciones de fuerza para controlar la escala de violencia. Con este objetivo en mente (Cockayne, 2014, p. 745), en diciembre de 2004 y en julio de 2005 se llevaron adelante grandes operativos militares en Cité Soleil, uno de los barrios bajos más importantes y estratégicos de Puerto Príncipe. Estas intervenciones fueron, sin embargo, de una corta duración y ambas representaron en última instancia un fracaso táctico y estratégico. Desde una perspectiva táctica MINUSTAH no logró asegurar la zona y continúo sin poder llevar adelante patrullas a pie por la misma. Desde un análisis más estratégico, el nivel de violencia y los daños colaterales provocados por la misión ${ }^{11}$ impactaron fuertemente sobre la reputación de los cascos azules y alienó a una parte significativa de la población (Cockayne, 2014, pp. 748 - 749). Podríamos discutir incluso si estas incursiones no habrían abierto la posibilidad a un aumento de la violencia al alterar el equilibrio de poder

\footnotetext{
${ }^{8}$ Las pandillas criminales de Haití suelen ser denominadas 'base' o 'baz' en Creole. Estas han sido caracterizadas como "grupos o redes informales con una autoridad con ciertos dejos políticos sobre un territorio" (Schuberth, 2017, p. 7). Junto con ejecutar un estilo de "justicia callejera" dentro de su barrio/territorio las $b a z$ han creado una narrativa en donde se presentan como defensores de su comunidad contra amenazas externas, sean éstas reales o percibidas, y provengan las mismas desde MINUSTAH, el Estado haitiano o una $b a z$ rival. En esencia estas pandillas han establecido un mecanismo que funciona como una combinación de extorsión y protección y son percibidas como dueñas de una estructura paraestatal dentro de los barrios populares (Schuberth, 2017, p. 7).

${ }^{9}$ Con este término nos referimos a lo planteado por el General Sir Rupert Smith en su texto The Utility of Force, cuando describe a organizaciones cuyas estructuras visibles (o superficiales), se encuentran sostenidas por densas redes subterráneas (Smith, 2012).

${ }^{10}$ Formalmente las Fuerzas Armadas de Haití $(F A d ' H)$ fueron disueltas en 1995. A pesar de que muchos de sus miembros fueron incorporados en la nueva Policía Nacional Haitiana (PNH), miles de sus efectivos quedaron desocupados y prestos a formar milicias armadas que han sido un factor de desestabilización posterior a la salida de Aristide del poder.

${ }^{11}$ Para la operación "Puño de Hierro" (6 de julio de 2005) fueron desplegados más de 400 efectivos en Cité Soleil con unas 1000 tropas adicionales destinadas a asegurar el perímetro. A pesar de este despliegue contundente, las pandillas logran inmovilizar a los cascos azules por más de 7 horas mientras que estos intentan extraer dos vehículos blindados del barro. Durante ese periodo de tiempo se contabilizaron el uso de 22.700 rondas de municiones y 78 granadas. El saldo de este enfrentamiento ascendió también a 23 inocentes quienes fueron atrapados en el fuego cruzado (Cockayne, 2014, pp. 748 - 749).
} 
entre las baz de la zona (Cockayne, 2014, pp. 745) mientras que a su vez enviaba una señal ambivalente al respecto del uso de la fuerza por parte de Naciones Unidas.

Según Guy Hammond (2012, p. 14) el fracaso inicial de MINUST AH a la hora de lidiar con la violencia en la isla se debió a: 1 . La falta de capacidad y voluntad del gobierno transicional para confrontar con las bandas armadas irregulares; 2. La cooperación forzada con la Policía Nacional de Haití (PNH), lo cual erosionó la legitimidad de la fuerza y al mismo tiempo la ató de manos operacionalmente; 3. La falta de una visión coordinada dentro del liderazgo de MINUSTAH durante el periodo. Hubo que esperar hasta la segunda mitad del 2005, y el despliegue de una nueva estrategia, para que la situación comenzara a ser revertida.

Partiendo del análisis de las pandillas urbanas, el control efectivo que poseen sobre su territorio, el apoyo popular que logran suscitar y los fracasos previos, se decidió a nivel estratégico por el empleo de tácticas que en la práctica son reminiscentes a las técnicas de clear-hold-build de la contrainsurgencia clásica. En ese sentido se realizaron operaciones militares para ocupar territorio en Cité Soleil y Bel Air, el cual luego sería consolidado mediante "proyectos de impacto rápido" (QIP, por sus siglas en inglés) y el establecimiento de una presencia más permanente. Finalmente se llevarían adelante "proyectos de economía comunitaria" (Schuberth, 2017, p. 8). Este modelo de intervención implicó el trabajo coordinado no sólo de las fuerzas de MINUSTAH y la PNH, sino también una cooperación con los elementos civiles y orientados al desarrollo que se encontraban en el terreno junto a la misión.

A la hora de llevar adelante su ofensiva militar, MINUSTAH comenzó a emplear de manera más consistente el uso de la inteligencia. En tal sentido, la creación del Joint Mission Analysis Centre (JMAC), el cual se consolidó como un espacio de coordinación entre oficiales militares, policías locales y administradores civiles internacionales, fue de vital importancia en ese proceso (Dorn, 2009, p. 807). El empleo de una extensa red de inteligencia humana y de señales (HUMINT y SIGINT) permitió a la estructura de mando de la misión entender y rastrear a las diferentes pandillas y sus miembros y de tal manera procurar anticipar sus movimientos. Siguiendo la tradición de la contrainsurgencia, en este marco, MINUSTAH determinó que el centro de gravedad de las baz lo constituían las comunidades locales. En ese sentido la población civil se convirtió en un terreno clave en esta lucha, dado que el apoyo de las mismas es lo que les permite prosperar a las baz (Cockayne, 2014, p. 756). Teniendo muy en claro este factor de "corazones y mentes" durante las operaciones militares se llevaron adelante dos tácticas concretas.

En primer lugar, luego de cada operación de combate el Batallón Brasileño (BRABATT) actuó rápidamente para intervenir la zona con QIP y "proyectos de impacto inmediato" (IIP) los cuales no sólo apuntaron a reparar los daños ocasionados por el combate, sino que también aspiraron a reemplazar aquellas funciones sociales que brindaban las baz (Schuberth, 2017, p. 8; Dorn, 2009, p. 819).

En segundo lugar, se comenzó a emplear la estrategia de los "Puntos Fuertes". Estos eran un dispositivo por medio del cual se apunta a establecer una proyección de fuerza en todas las direcciones del área a ser controlada, mientras que de manera simultánea permite a las fuerzas de seguridad (en este caso, los miembros del Batallón Brasileño) guarecerse de ataques de las fuerzas irregulares (Novaes Miranda, 2018, p. 54). Otra ventaja del empleo de este mecanismo es la posibilidad de usar esos espacios para desplegar patrullas por la zona. En el área de influencia de cada "Punto Fuerte" (la cual representaba un radio de 200 metros) el oficial junior a cargo se encontraba con total libertad de acción para perseguir el objetivo de pacificar su sector (Novaes Miranda, 2018, p. 54). Esto nos trae reminiscencia de las técnicas mencionadas más arriba a la hora de describir operaciones de contrainsurgencia. En palabras del General de División André Luis Novaes Miranda (2018, p. 54), el teniente a cargo de cada pelotón debía actuar con:

rapidez, iniciativa y oportunidad a través de patrullas a pie, patrullas motorizadas, mecanizadas y mixtas, establecimiento de puestos de observación (PO), [...] puntos de 
control relámpagos y fijos, pequeños "Puntos Fuertes", búsquedas de área, registros de población y otras acciones apropiadas.

Un elemento central en este esquema, y en el que nuevamente encontramos una similitud táctica entre las acciones de MINUSTAH y los postulados de la contrainsurgencia, es a la hora de analizar el margen de acción para el uso de la fuerza armada con el que contaban los efectivos en el terreno. Caldas Mendoça (2017, pp. 740-742), al realizar un análisis de las reglas de empeñamiento de MINUSTAH, señala que tanto este texto como las obras de Galula y Trinquier presentan similitudes al perseguir una utilización mesurada de la fuerza, contener los daños colaterales en pos de atraer a la población y finalmente de plantear la noción de pacificación/estabilización como sinónimo de control militar.

Una vez garantizada la seguridad en la zona se comienza a incorporar más activamente a los actores locales (PNH, Estado), actores de la sociedad civil e incluso al sector privado. A modo de ejemplo podemos mencionar algunos de los programas que consideramos claves en el proceso. Por un lado, un extenso proyecto de reforma del sector de seguridad (RSS o SSR por sus siglas en inglés) que apunta a incorporar elementos de policiamiento comunitario y de proximidad con técnicas orientadas a solución de problemas (Schuberth, 2017, p. 12). Por otro lado, MINUSTAH en conjunto con la ONG "Viva Río" llevaron adelante programas "Comunitarios de Reducción de la Violencia" (CVR por sus siglas en inglés). Estos programas buscan combinar la prevención de la violencia y la reducción de la misma junto con un marco amplio de desarrollo, trabajando en barrios marginales. El objetivo de los mismos es generar las oportunidades económicas y sociales para cortar de raíz el influjo de nuevos reclutas a las baz, al mismo tiempo que competir por los "corazones y mentes" de los civiles delineando una narrativa favorable hacia MINUSTAH y la presencia estatal (Mendoça, 2017, pp. 12-14).

Para finales del 2007 la situación de seguridad se hallaba prácticamente controlada y el force commander, el General Santos Cruz (Mendoça, 2017, p. 98), podía declarar que la Misión había logrado retomar el control de todo el territorio nacional. Sin embargo, estos éxitos demostraron ser superficiales, dado que nunca se logró eliminar de raíz la vinculación entre criminalidad y las élites político-económicas de la isla, a su vez que los planes para una estrategia de desarrollo a más largo plazo nunca se asentaron (Cockayne, 2014, p. 763). Estas falencias salieron a la luz de manera violenta en 2010 luego de la destrucción provocada por el terremoto que acaeció en el país.

En esta sección pudimos apreciar cómo, a la hora de llevar adelante el mandato de estabilizar Haití, el contingente brasileño empleó en la práctica todos los elementos del manual de contrainsurgencia mencionados más arriba. A continuación, nuestro recorrido nos devuelve a Río de Janeiro en donde nos detendremos en el establecimiento y las prácticas de las UPP.

\subsection{Regresamos a Río de Janeiro}

Como mencionamos previamente en este trabajo, las intervenciones en las favelas de Río históricamente estaban orientadas hacia un enfoque represivo, caracterizándose por incursiones militares coercitivas de corta duración (Werling, 2014, p. 2). En el año 2008 y bajo un clima de desborde social, causado por una nueva escalada de violencia entre facciones criminales y entre éstas y la policía, se buscó generar una estrategia conjunta que involucrara a los 3 niveles de gobierno (Sampó, Quiros y Petrino, 2019, p. 11). Es así que de la mano del Gobernador Sergio Cabral y el Intendente Eduardo Paes, se lanza la Unidad de Pacificación Policial (UPP). Dicho plan fue posible dada la alianza fortuita entre las fuerzas políticas al mando del municipio, el Estado y la Nación. Tanto el Gobernador como el Intendente eran miembros del Partido del Movimiento Democrático Brasileño (PMBD) el cual en ese momento había trabado una alianza con el Partido de los Trabajadores (PT) el cual controlaba la primera magistratura (Foley, 2014, p. 28). 
Este programa que integra intervenciones represivas de seguridad con componentes de desarrollo social se delineó en 3 etapas (Werling, 2014, p. 2):

1. Intervención táctica, en donde la PMRJ (especialmente el Batallón de Operaciones Policiales Especiales - BOPE), con apoyo del ejército y de los fuzileiros navales, apuntaron a recuperar el territorio en mano de las bandas criminales.

2. Estabilización, destinada a calmar y asegurar esas áreas.

3. Consolidación, mediante el despliegue permanente de las UPP.

Dentro del planteo precedente podemos identificar, sin mucha dificultad, la tríada básica de clear-hold-build que se encuentra en el corazón de la doctrina de la contrainsurgencia. Bajo dicho esquema, la pacificación buscó lidiar con las múltiples causas de la violencia de Río a través de los mecanismos coercitivos que planteamos más arriba y complementados con una agenda de desarrollo y urbanización.

Una vez garantizada la seguridad e instalados los Posto de Policiamento Comunitário (PPC) se buscó facilitar el diálogo y asociación entre los residentes y las fuerzas de seguridad estatales de manera tal que se fortalecieran liderazgos locales positivos (Cano, 2012). Es en ese momento que se activa el otro componente del plan, el denominado UPP Social. Mediante el uso de coordinadores locales (Foley, 2014, p. 30), los cuales destinan entre 2 a 3 semanas para establecer vínculos con las asociaciones vecinales, líderes locales y la población general, se procuraba obtener una panorámica de las principales demandas de estos actores. El paso siguiente era realizar un ejercicio de Diagnóstico Rápido Participativo el cual proveía una evaluación socioeconómica de cada favela. Basado en ese primer acercamiento se llevaron adelante diversos Foros de UPP Social en donde participaron funcionarios de entre 15 a 20 dependencias públicas sumados a representantes del sector privado y de la sociedad civil (Cano, 2012) y en donde se crearon planes para brindar asistencia sanitaria, educación, programas de empleo, servicios formales y principalmente garantizar la presencia permanente del Estado, reemplazando a los grupos armados como proveedores de estos servicios (Werling, 2014, pp. 4-5). El objetivo era consolidar y fortalecer los avances de seguridad, ganando el apoyo de la población hacia el Estado.

La conexión entre MINUSTAH y las operaciones urbanas en Río es clara al identificar que los efectivos que participaron en las dos primeras operaciones de "pacificación" de Vila Cruzeiro y el Complexo do Alemão en 2010, denominada Operação Arcanjo, habían visto combate en la etapa más violenta de la ofensiva contra las baz en Puerto Príncipe (Hoelscher \& Norheim-Martinsen, 2014, p. 964).

Siguiendo a Rodríguez (2016) vemos a su vez cómo existió una fuerte semejanza entre los objetivos generales de ambas operaciones. En el caso de la misión de Naciones Unidas el objetivo era promover un ambiente seguro y estable para asistir a la recuperación de la seguridad y el orden público; por su parte, en Río, la intervención en Penha y Alemão se realizó para asistir a la preservación del orden público de dichas comunidades (Rodrigues, 2016, p. 73).

El Coronel Alberto de Lima (2012) al narrar su experiencia en la Operação Arcanjo relata un conjunto de tareas que no se distinguen de aquellas empleadas en Haití. En tal sentido el primer objetivo de la Força de Pacificaçao fue la ocupación permanente de "Puntos Fuertes" para control del área a ser pacificada, Puntos de Visibilidad para proyectar la presencia de la fuerza ante la población civil, constantes patrullas a pie y motorizadas y acciones de búsqueda y aprehensión en base a información obtenida por operaciones de inteligencia (Lima, 2012, p. 58). Sin descuidar el aspecto social, la Força de Pacificaçao buscó generar una aproximación a los referentes barriales, apoyar acciones educativas en escuelas, la realización de una amplia gama de acciones cívicosociales (ACISOS) y operaciones en conjunto con órganos municipales y estaduales a fin de desincentivar contravenciones (Lima, 2012, p. 58). Al respecto, Lima (2012, p. 94) destaca la necesidad de conquistar la confianza de la población para el triunfo de una operación de estas características, y de tal manera, se asemeja a los planteos realizados por Galula y Triquier sobre la importancia del frente político de la intervención. Nuevamente percibimos a la población civil 
como uno de los terrenos claves a ser conquistados mediante operaciones psicológicas delineadas a tal fin (Lima, 2012).

A pesar de que se complementaron estas operaciones con programas de policiamiento comunitario, la tendencia continuó siendo una intervención forzosa por parte de las Fuerzas Armadas y de la PMRJ con las organizaciones criminales de las favelas. Si bien se ha planteado que estos acercamientos son necesarios en un primer momento para reimplantar la presencia del Estado en estas comunidades de manera segura, nosotros entendemos junto con Hoelscher \& Norheim-Martinsen (2014, p. 964) que lo que se logra es reafirmar la narrativa que promueve la reinstauración de la paz vía el uso de la fuerza. La mentalidad militar continúa siendo visible (si no dominante) en el modo en el que la seguridad urbana es tratada en Río de Janeiro. Para parafrasear a Rupert Smith (2012) se ha planteado una visión en la que se sostiene la "utilidad de la fuerza" en la medida en que el control territorial aún se plantea como una precondición para vincularse con la comunidad local (Hoelscher \& Norheim-Martinsen, 2014, p. 966). Como hemos visto durante este trabajo, ésta es la idea fuerza detrás de la doctrina de la contrainsurgencia.

Siguiendo a Sampó, Quiros y Petrino (2019, p. 12), tras un primer periodo (2008-2014) en el cual se observó una reducción de los índices de violencia en las comunidades, se comienza a percibir un cambio de tendencia y estos mismos índices nuevamente empiezan a subir ante el "contraataque" de grupos criminales como el Comando Vermelho, quienes comenzaron una activa campaña contra la UPP (Ramos da Cruz \& Ucko, 2018, p. 21). En ese contexto, y ante la inminencia de mega-eventos ${ }^{12}$ deportivos a realizarse en la ciudad, las UPP se vieron incentivadas a incrementar el carácter militarizado de su intervención (Sampó, Quiros y Petrino, 2019, p. 13). En paralelo, el máximo atributo con el cual contaba el programa, el apoyo político detrás del mismo, comienza a flaquear a partir de las elecciones del 2010, suscitando desacuerdos jurisdiccionales entre la ciudad y el estado. El cambio de balance en la legislatura estadual provocó que el equipo a cargo de UPP Social se relocalizara en la órbita municipal bajo la administración del Instituto Pereira Passos. Por su parte el gobernador creó un nuevo programa social denominado Territórios da Paz. A pesar de mantener su nombre, UPP Social no poseía un vínculo formal con las UPP, mientras que su "reemplazo" (Territórios da Paz) contó desde el comienzo con menos financiación y un perfil mucho más bajo. Como consecuencia de lo anterior, UPP Social fue despojado de su mandato de implementación y transformado en un "instituto de investigación urbano" el cual carecía de la capacidad de coordinar la puesta en marcha de los proyectos sociales (Schuberth, 2017, p. 10). Vale la pena resaltar que en ningún momento ninguna de estas iniciativas logró, efectivamente, establecer mecanismos de accountability de las comunidades pacificadas sobre las UPP (Foley, 2014).

La escalada de violencia referida más arriba culmina con 2017 como uno de los años más violentos de la historia de la ciudad en el Siglo XXI (Sampó, Quiros y Petrino, 2019, p. 14), y finalmente con la decisión del gobierno federal de Brasil de intervenir militarmente a Río de Janeiro, marcando la defunción efectiva del programa.

Según lo planteado por Ramos da Cruz y Ucko (2018) se combinaron una serie factores que erosionaron la efectividad de las UPP hasta el punto de hacer fracasar la iniciativa. En principio, al obtener los primeros resultados satisfactorios, la UPP se expandió demasiado rápido a varias comunidades produciendo beneficios marginales decrecientes. Por otro lado, ni las poblaciones de las favelas ni los mismos miembros de la fuerza hicieron efectivamente propios el plan. Mientras que los primeros lo percibieron como una nueva forma de gobernanza no representativa, los agentes de policía descreyeron de su efectividad en el largo plazo. Finalmente, como habíamos adelantado más arriba, los grupos criminales desplazados por las UPP, y las operaciones previas a su implantación, comenzaron una contraofensiva destinada a erosionar la imagen del programa junto con asaltos armados que apuntaban a debilitar la presencia de las mismas en las diversas comunidades.

\footnotetext{
${ }^{12}$ Copa del Mundo FIFA 2014 y Olimpíadas de Verano 2016.
} 
Frente a todo lo mencionado, sería un error ver la estrategia de "pacificación" como una simple remilitarización de la vigilancia de las favelas. Más bien representa una nueva forma de operaciones de seguridad, influenciada por las experiencias de Brasil en Haití, pero informada a su vez por una tradición de técnicas de contrainsurgencia con décadas de presencia en el ADN de las Fuerzas Armadas del país. Las UPP representan la última iteración en territorio brasileño de ese mecanismo represivo que busca emplear técnicas de "zanahoria y garrote" para obtener el control de zonas urbanas identificadas como conflictivas.

\section{Reflexiones finales}

A lo largo de este trabajo hemos sostenido que la práctica de los efectivos militares brasileños en Haití y en las diferentes misiones de pacificación representa una aplicación de los principios básicos de la contrainsurgencia francesa.

Entendida en su versión contemporánea, la contrainsurgencia, surge en el Siglo XIX para enfrentar movimientos contestatarios a la dominación colonial de París. Esta doctrina pone su foco en la población y genera un conjunto de técnicas para poder insertar la presencia estatal en el territorio en disputa con el objetivo de erradicar violentamente a las fuerzas insurgentes mientras que de manera paralela lleva adelante acciones destinadas a ganar el favor de los civiles. Un elemento que distingue esta forma de hacer la guerra de las demás es la importancia capital que se le presta a las ramificaciones políticas de las operaciones de combate, y la centralidad de la batalla por los "corazones y mentes" de la población a la cual se pretende proteger de actores armados peligrosos.

La presencia de dicha influencia francesa entre las Fuerzas Armadas de Brasil precede tanto al despliegue en MINUSTAH como a la creación de las UPP. Como hemos planteado más arriba la doctrina de la contrainsurgencia comenzó a ser incorporada por los oficiales del ejército de Brasil durante la década del ' 50 , y fue implementada durante la dictadura militar acaecida entre los años 1964 y 1985. Estas experiencias serán aplicadas bajo el mandato de las primeras operaciones de GLO a principios del '90 en el marco de una guerra diferente. En este caso el enemigo interno, "el subversivo/insurgente" será identificado como el favelado a quien se lo asociará con el narcotráfico. Este know-how represivo será empleado a su vez en Puerto Príncipe ya que, de acuerdo a miembros del BRABATT desplegados en Haití, MINUSTAH requirió las mismas "tácticas, técnicas y procedimientos" que las Operaciones de GLO (Pinheiro, 2009, p. 7). De esa manera, las acciones realizadas por los primeros 6 contingentes brasileños implementaron los lineamientos plasmados en los manuales de GLO para llevar adelante la pacificación del área (da Cunha, 2008, p. 85).

Si aplicamos la analogía histórica de Argelia hallamos que, por un lado, el BOPE en Río y el BRABATT en Puerto Príncipe, reprodujeron las tácticas enfocadas en el enemigo de las razzias por medio de incursiones fuertemente armadas a las comunidades y las técnicas de control militar del territorio en disputa. Por el otro lado, encontramos el aspecto más "constructivo" de los bureaux arabes en los programas coordinados por el GPAE y UPP Social en las favelas y los proyectos de CVR llevados adelante por "Viva Río" en la nación caribeña.

Si bien se tiende a retratar a la conexión entre Puerto Príncipe y Río como un canal unilateral en donde MINUSTAH es el origen de las operaciones posteriores en los morros de la capital carioca, la realidad es más compleja. Las UPP son el último estadio en un proceso de perfeccionamiento de técnicas de control urbano, las cuales toman esas experiencias desarrolladas a finales del Siglo XX por el ejército de Brasil y son exportadas a las calles de Cité Soleil y Bel Air, donde son pulidas y luego reimportadas a Río de Janeiro.

A pesar de que tanto las técnicas empleadas en Haití como en Río de Janeiro en un principio parecieron producir los resultados esperados, en ningún momento atendieron a los problemas estructurales que originaron esas situaciones en primer lugar. Tanto en la nación 
caribeña como en los morros de Río, una verdadera paz es todavía esquiva para la mayoría de sus habitantes.

\section{Bibliografía}

Bonnet, G. (1963). Les Guerres Insurrectionnelles et Révolutionnaires. Río de Janeiro: Biblioteca do Exército Editora

Caldeira, T. (2002). The Paradox of Police Violence in Democratic Brazil. Ethnography, pp. 235263

Cano, I. (2012). Os Donos do Morro: Uma Avaliacao Exploratoria do Impacto das Unidades de Policia Pacificadora UPPs no Rio de Janeiro. Fórum Brasileiro de Seguranca Pública

Cardia, N. (2000). Urban ViolenceinSãoPaulo. Comparative Urban Studies Occasional Papers Series. Washington: Woodrow WilsonInternationalCenter for Scholars

Cardia, N., Adorno, S., \& Poleto, F. (2003). Homicide Rates and Human Rights Violations in São Paulo, Brazil: 1990 to 2002. Health and Human Rights, pp. 14-33

Carlson, E. (2000). The Influence of French 'Revolutionary War' Ideology on the Use of Torture in Argentina's 'Dirty War'. Human Rights Review, 1(4), pp. 71-84

Chisholm, R. (2018). Counterinsurgency, Military Education, and the Erosion of Apolitical Professionalism: Lessons from the french and brazilian experiences. Romanian Journal of Society \& Politics, 13(2), pp. 7-33

Cockayne, J. (2009). Winning Haiti's protection competition: Organized crime and peace operations past, present and future. International Peacekeeping, 16(1), pp. 77 - 99

Cockayne, J. (2014). The Futility of Force? Strategic lessons for dealing with unconventional armed groups from the UN's war on Haiti's gangs. Journal of Strategic Studies, 37(5), pp. 736-769

Costa, O. (1994). Depoimento. En M. D'Araujo, G. Dillon Soares, \& C. Castro, Visões do Golpe: A Memória Militar sobre 1964. Rio de Janeiro: Relume Dumará

da Cunha, J. (2008). A Experiência Operacional do 7o Contingente do Batalhão Brasileiro no HAITI: Mudança de Fase. Coleção Meira Mattos - Revista das Ciências (19), pp. 19-32

Dorn, A. W. (2009). Intelligence-led Peacekeeping: The United Nations stabilization mission in Haiti (MINUSTAH), 2006-07. Intelligence and National Security, 24(6), pp. 805 - 835

Foley, C. (2014). Pelo telefone: Rumors, truths and myths in the 'pacification'of the favelas of Rio de Janeiro. Rio de Janeiro: HASOW Discussion Paper

Galula, D. (1964). Counter-insurgency Warfare: Theory and practice. Londres: Praeger

Hammond, G. (2012). Saving Port-au-Prince: United Nations Efforts to Stem Violence against Civilians in Haiti 2006 - 2007. Washington DC: Stimson Centor

Harig, C. (2015). Synergy Effects Between MINUSTAH and Public Security in Brazil. Brasiliana journal for brazilian studies, 3(2), pp. 142-168

Harig, C. (2019). Re-importing the "Robust Turn" in UN Peacekeeping: internal public security missions of Brazil's military. International Peacekeeping, 26(2), pp. 137-164 
Hoelscher, K., \& Norheim-Martinsen, P. M. (2014). Urban Violence and the Militarisation of Security: Brazilian 'peacekeeping'in Rio de Janeiro and Port-au-Prince. Small Wars \& Insurgencies, 25(5-6), pp. 957-975

International Crisis Group. (2007). Consolidating Stability in Haiti

Kilcullen, D. (2012). Counterinsurgency: The state of a controversial art. En P. Rich, \& I. Duyvesteyn, The Routledge Handbook of Insurgency and Counterinsurgency (pp. 128153). New York: Routledge

Koonings, K., \& Kruijt, D. (2007). Fractured Cities. Social exclusion, urban violence and contested spaces. London: Zed Books

Koonings, K., \& Kruijt, D. (2009). Megacities: The politics of urban exclusion and violence in the Global South. London: Zed Books

Lemay-Hébert, N. (2014). Resistance in the Time of Cholera: The limits of stabilization through securitization in Haiti. International Peacekeeping, 21(2), pp. 198-213

Lima, C. (2012). 583 Dias da Pacificação dos Complexos do Alemão e da Penha. Rio de Janeiro: Agência A2 Comunicações

Martine, G., \& McGranahan, G. (2010). Brazil's Early Urban Transition: What can it teach urbanizing countries? Urbanization and Emerging Population, (4), pp. 1-74

Martins Filho, J. (2014). Military Ties Between France and Brazil During the Cold War, 19591975. Latin American Perspectives, 41(5), pp. 167-183

Mendoça, T. C. (2017). Pacificação e Contrainsurgência: As forças de pacificação do Exército brasileiro nos Complexos do Alemão e da Penha (2010-2012). Niterói: Universidad Federal Fluminense

Ministère de la Défense de la République Française. (2010). Sécurité, Développement, Gouvernance: Contribution des Forces Armées à la Stabilisation

Misse, D., \& de Carvalho, R. (2008). Policiamento Comunitário no Rio de Janeiro. Anais do XVI Congresso Nacional do CONPEDI - Pensar Globalmente: Agir Localmente (pp. 66706681). Belo Horizonte: Fundação Boiteux

Moser, C. O. N.. (2004). Urban Violence and Insecurity: AnIntroductory roadmap. Environment \& Urbanization, 16(2), pp. 3-16

Novaes Miranda, A. L. (2018). A Pacificação de Bel Air. En E. Hamann, \& C. Ramires Teixeira. A participação do Brasil na MINUSTAH (2004-2017): percepções, lições e práticas relevantes para futuras missões (págs. 51 - 57). Rio de Janeiro: Instituto Igarapé \& Centro Conjunto de Operações de Paz do Brasil (CCOPAB)

Perelli, C. (1992). Settling Accounts with Blood Memory: The case of Argentina. Social Research, 59(2), pp. 415-451

Perlman, J. (2010). Favela: four decades of living on the edge in Rio de Janeiro. New York: Oxford University Press

Petraeus, D., \& Amos, J. (2009). FM 3-24 2006 Counterinsurgency. Washington DC: Paladin

Pinheiro, A. (2009). A Segurança Pública, o Exército Brasileiro e as Operações de Garantia da Lei e da Ordem. Estudos e Pesquisas, 322, pp. 1-7

Porch, D. (2013). Counterinsurgency: Exposing the Myths of the New Way of War. Cambridge: Cambridge University Press

Ramos da Cruz , C., \& Ucko, D. (2018). Beyond the Unidades de Polícia Pacificadora: Countering Comando Vermelho's Criminal Insurgency. Small Wars \& Insurgencies, 29(1), pp. 3867 
Rid, T. (2010). The Nineteenth Century Origins of Counterinsurgency Doctrine. The Journal of Strategic Studies, 33(5), pp. 727-758

Rodgers, D. (2009). Slum Wars of the 21st Century: Gangs, mano dura and the new urban geography of conflict in Central America. Development and Change, 19(4), pp. 949-976

Rodrigues, T. (2016). Narcotráfico, militarização e pacificações: novas securitizações no Brasil. En R. Passos, \& A. Fuccille, Visões do Sul: crise e transformações do sistema internacional (pp. 55-88). São Paulo: Cultura Acadêmica

Sampó, C. y Troncoso, V. (2015). La Violencia Vinculada a la Criminalidad en Brasil y el Papel de las Fuerzas Armadas en la Búsqueda de la Seguridad Pública. Revista de Relaciones Internacionales, Estrategia y Seguridad, 10(1), pp. 89 - 109

Sampó, C., Quiros, L. y Petrino, J. (2019). La Guerra Urbana en Rio de Janeiro: De las Unidades de Policía Pacificadora a la Militarización (2008-2018). Revista Relaciones Internacionales, Estrategia y Seguridad, 14(1), pp. 151 - 161

Sanchez, M. (2006). Insecurityand Violenceas a New PowerRelation in LatinAmerica. The ANNALS of the American Academy of Political and Social Science(606), pp. 178-195

Schuberth, M. (2017). Disarmament, Demobilization and Reintegration in Unconventional Settings: The case of MINUSTAH's community violence reduction. International Peacekeeping, 24(3), pp. 410-433

Smith, R. (2012). The Utility of Force: The art of war in the modern world. UK: Penguin

Svartman, E. (2006). Guardiões da Nação: Formação professional, experiências compartilhadas e engajamento político dos generais de 1964. Porto Alegre: Universidade Federal do Rio Grande do Sul

Trinquier, R. (2006). Modern Warfare: a French view of counterinsurgency. Westport: Greenwood Publishing Group

UK Government - Stabilization Unit. (2014). The UK Government's Approach to Stabilization.

UNHABITAT. (2007). Enhancing Urban Safety andSecurity: global reporton human settlements 2007. London: Earthscan.

US Joint Chiefs of Staff. (2016). Stability - Joint Publication 3-07

Werling, E. (2014). Rio's Pacification: Paradigm shift or paradigm maintenance. Humanitarian Action in Situations others than War

Winton, A. (2004). Urban Violence: A guide to the Literature. Environment and Urbanization, 16(2), pp. 165-184

World Bank. (2011). World Development Report2011.Conflict, Security, andDevelopment. Washington D.C.: The World Bank 